\title{
Measurement of temperature and gas concentration in a flame using a FTIR imager
}

\author{
M. A. Rodríguez ${ }^{1}$, G. Guarnizo ${ }^{1}, J$. Meléndez $^{1}, F$. López $^{1}$, J. M. Mantilla ${ }^{2 *}$, M. J. Martin ${ }^{2}$, D. del Campo ${ }^{2}$ \\ ${ }^{1}$ LIR-Infrared Lab. Departamento de Física, Universidad Carlos III de Madrid, Av. Universidad, 30, Leganés, Madrid (Spain) \\ ${ }^{2}$ Centro Español de Metrología, CEM, C/ del Alfar, 2. Tres Cantos, Madrid (Spain)
}

\begin{abstract}
Nowadays, determining the temperature of flames is a challenging measurement in industry. The EMPIR project 14IND04 EMPRESS, in its WP4, address these temperature measurements. The Infrared Lab at the Physics Department of Universidad Carlos III of Madrid (UC3M) has developed a technique for measuring the temperature of a standard flame, in collaboration with the Centro Español de Metrología (CEM). An Imaging Fourier Transform Spectrometer (FTIR) has been used to acquire the emitted radiation coming from the flame and establish its temperature through several processing stages. This equipment has been calibrated with standard radiation thermometers and blackbodies at CEM.
\end{abstract}

\section{Introduction}

Thermometry in flames needs to be non-invasive and non-perturbing and the "probe" must be capable of withstanding temperatures in the range of $700{ }^{\circ} \mathrm{C}$ to $2700{ }^{\circ} \mathrm{C}$. These requirements indicate that optical methods will be a preferred option. The current state of the art in optical methods favours active probing using laser-based techniques but passive techniques such as emission spectroscopy are also possible. These techniques have been applied to situations such as sparkignition engines, burner optimizations, high temperature gas furnaces and incinerators in an effort to improve processes efficiencies and for example, reduce pollutant levels. However, uncertainties are difficult to assess at these processes. Conservative estimates of uncertainty are often used and can typically amount to between $5 \%$ and $10 \%$ of the processes temperature.

The EMPIR project 14IND04 EMPRESS in its WP4 addresses this industrial challenge. The aim of this work package is to develop and characterise a portable standard flame with a known and reproducible temperature (over $1700{ }^{\circ} \mathrm{C}$ ) and species concentrations [1]. Different groups will be brought together to calibrate the standard flame with different optical methods and to reduce uncertainty of measuring flames in industry.

The Infrared Lab at the Physics Department of Universidad Carlos III of Madrid (UC3M) has measured this standard flame, in collaboration with the Centro Español de Metrología (CEM). An imaging Fourier transform spectrometer (FTIR) has been used to acquire the emitted radiation coming from the flame.

\section{Description}

The device is based on a Michelson interferometer coupled to a InSb array of detectors (320x256 pixels) operating in the mid-infrared spectral range, from 1.5 $\mu \mathrm{m}$ to $5.5 \mu \mathrm{m}$ (see fig. 1 ).

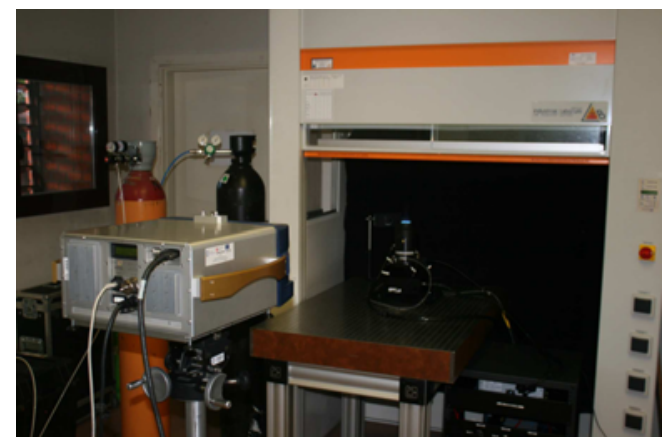

Fig. 1. View of the imaging FTIR (at the forefront) and the portable standard flame (at the background).

Blackbodies (BBs) and standard radiation thermometers (RTs) of CEM have been employed to calibrate the instrument for flame temperatures up to $2400{ }^{\circ} \mathrm{C}$.

For the calibration at CEM, large aperture blackbodies of $70 \mathrm{~mm}$ of diameter have been used at $180{ }^{\circ} \mathrm{C}$ and 400 ${ }^{\circ} \mathrm{C}$ (see fig. 2). The BBs temperature has been measured with a RT HEITRONICS TRTII working at $3.9 \mu \mathrm{m}$, traceable to the national standards. Also, CEM has measured the thermal uniformity at $200{ }^{\circ} \mathrm{C}$ and $400{ }^{\circ} \mathrm{C}$

*Corresponding author: jmmantilla@cem.minetur.es

C The Authors, published by EDP Sciences. This is an open access article distributed under the terms of the Creative Commons Attribution License 4.0 (http://creativecommons.org/licenses/by/4.0/). 
across the $14 \mathrm{~cm} \times 14 \mathrm{~cm}$ central area of a plane radiator, used to characterise the homogeneity of the FTIR's InSb detector array before flame measurements.

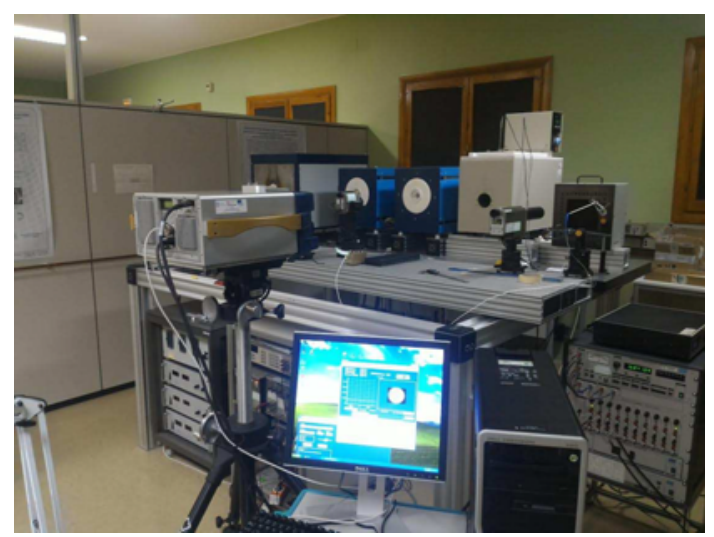

Fig. 2. View of the calibration facilities at CEM.

\section{Results}

A radiometric model [2] that takes into account background emission, atmospheric absorption, flame emission and flame absorption has been used to generate simulated radiance spectra.

The starting point is a radiative transfer model in the mid-infrared range (from $1.5 \mu \mathrm{m}$ to $5.5 \mu \mathrm{m}$ ), that incorporates the high temperature absorption/emission parameters of combustion gases (mainly $\mathrm{CO}_{2}, \mathrm{CO}$ and $\mathrm{H}_{2} \mathrm{O}$ ). Both temperature and species column densities are simultaneous obtained, for each pixel of the image, as a result of fitting measured spectra by the spectra provided by the model, as can be seen on figure 3 . Since the model generates full radiometric simulations of the flame emission, it provides a quantitative estimation of the systematic errors due to temperature non-uniformity along the integration path.
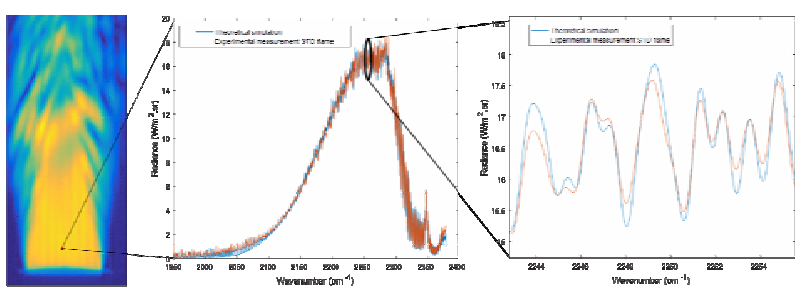

Fig. 3. Example of fitting between measured spectra and simulated spectra for a central pixel of the standard flame.

To make this approach operative, a full adaptation of the hyperspectral system to the specific problem of the flame radiance measurement has been performed in terms of dynamic range, spectral and spatial resolution and radiance calibration. It has been also necessary to develop ad-hoc processing procedures, specially focused on the correction of the flame's brightness fluctuations (flickering), data complexity reduction and signal to noise ratio enhancement [3].
The calibration has been made at $180{ }^{\circ} \mathrm{C}$ and $400{ }^{\circ} \mathrm{C}$. Because of the principle of operation of the interferometer, that records the signal in the full spectral interval and provides spectral resolution by a Fourier Transform, blackbodies at moderate temperatures may cover the full scale radiance, due to the narrow spectral emission of the flame.

The stability (standard deviation) of the $\mathrm{BBs}$ is $0.11^{\circ} \mathrm{C}$ at $400{ }^{\circ} \mathrm{C}$ and $0.09{ }^{\circ} \mathrm{C}$ at $180{ }^{\circ} \mathrm{C}$. The emissivity of the BBs used for the calibration has been calculated with STEEP3 ${ }^{\circledR}$ software and is 0.981 at $180{ }^{\circ} \mathrm{C}$ and 0.985 at $400{ }^{\circ} \mathrm{C}$. The uncertainty in $\varepsilon$ is $0.002(k=2)$, this implies $0.26^{\circ} \mathrm{C}$ at $400{ }^{\circ} \mathrm{C}$ and $0.12^{\circ} \mathrm{C}$ at $180{ }^{\circ} \mathrm{C}(k=2)$.

The RT HEITRONICS TRTII has been calibrated with respect to the standards of the laboratory $\left(U=0.3{ }^{\circ} \mathrm{C}\right)$. The final uncertainty of the temperature of the blackbodies is $0.5^{\circ} \mathrm{C}$.

Because the FTIR takes an image of the hot area, it is needed to determine the uniformity of the detectors array. This has been done with a large area radiator. The temperature uniformity of this radiator is shown in figure 4. It has been taken into account in the final uncertainty budget.

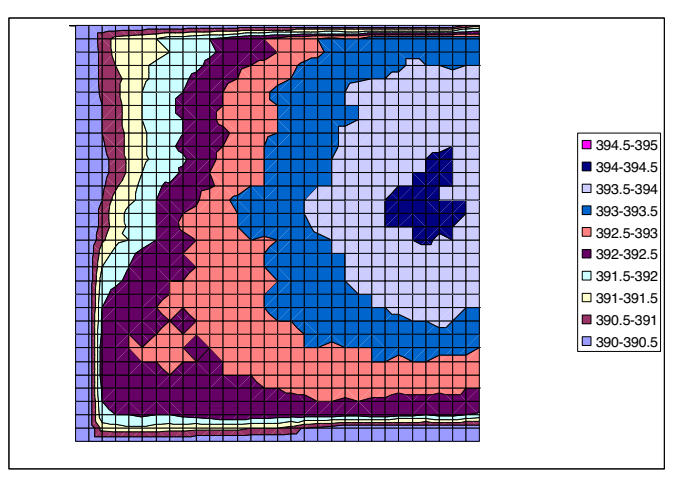

(a)

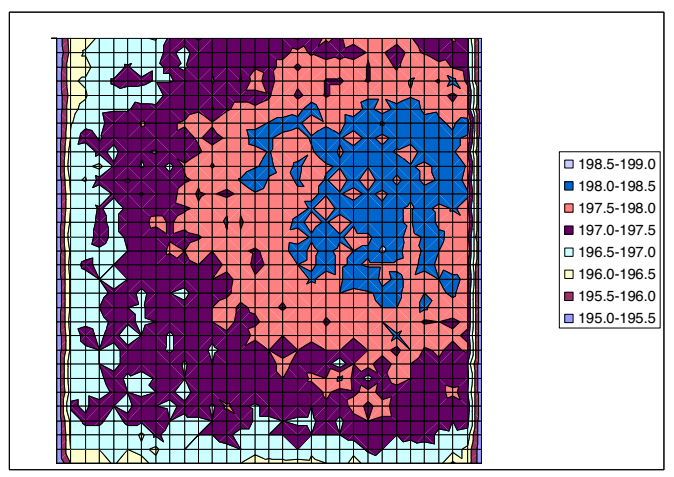

(b)

Fig. 4. Uniformity of the large area radiator used to determine the homogeneity of the imager FTIR (a) $400{ }^{\circ} \mathrm{C}$ (b) $200{ }^{\circ} \mathrm{C}$.

The standard flame developed by NPL has been measured applying this technique and first results have been published [1]. A sample of the results obtained is shown in figure 5 . The measurements done with FTIR 
match pretty with the ones done with Raleigh scattering technique (NPL) [1]. The preliminary differences are $<10 \mathrm{~K}$ a $T \cong 2250{ }^{\circ} \mathrm{C}(U=0.6 \%$ [5]).

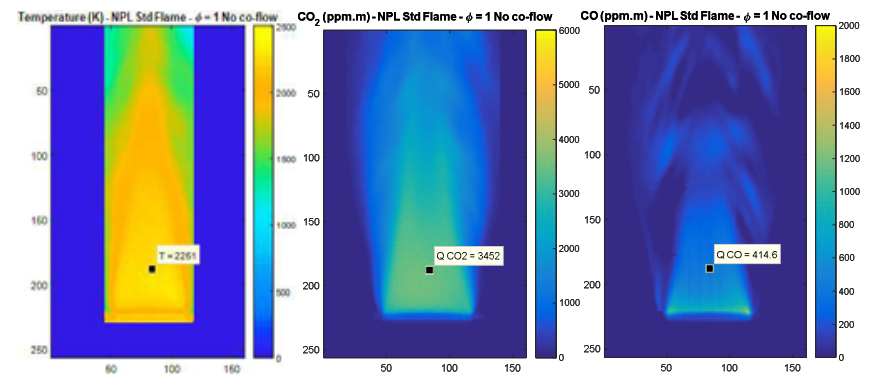

Fig.5. Images of physical features of the standard flame with an equivalent ratio value $\phi=1$, with $\mathrm{N}_{2}$ co-flow. Left: Temperature. Centre: $\mathrm{CO}_{2}$ column density. Right: $\mathrm{CO}$ column density. The particular value at a point located $20 \mathrm{~mm}$ above the burner centre is indicated in each image.

\section{Conclusions}

The temperature of a portable standard flame has been measured with an imaging FTIR with an uncertainty of $0,6 \%$ up to $2250{ }^{\circ} \mathrm{C}$. The main advantages of this technique are:

- The simplicity of the experimental arrangement, that measures remotely and no intrusively, with a minimum setup.

- The capability of spatial resolution, that provides a wealth of useful information of flame structure. Since the hyperspectral imaging system acquires several hundred images of the flame per second, even flame dynamics can be studied,

Acknowledgements: This research is partially included in an EMPIR Joint Research Project 14IND04 EMPRESS, jointly funded by the EMPIR participating countries within EURAMET and the European

\section{References}

1. G. Sutton. EMPRESS Workshop, Glasgow, UK, (2017)

2. M. A. Rodríguez-Conejo, J. Meléndez. Appl. Opt. 54(2), 141-9 (2015)

3. M. A. Rodriguez-Conejo. Doctoral thesis, UC3M (2016)

4. M. A. Rodríguez-Conejo, G. Guarnizo, J. Meléndez, F. López, M. J. Martín, J. M. Mantilla, D. del Campo. TEMPMEKO'16, Zakopane, Polonia (2016)

5. J. Meléndez, G. Guarnizo. Report on UC3M measurements on NPL standard flame. Internal Report, UC3M (2017) 